J. Felix, A. Klimczuk, Social Entrepreneurship and Social Innovation in Aging, [in:] D. Gu, M.E. Dupre (eds.), Encyclopedia of Gerontology and Population Aging, Springer, Cham 2020, pp. 1-8, https://doi.org/10.1007/978-3-319-69892-2 242-1.

\title{
Social Entrepreneurship and Social Innovation in Aging
}

Jorge Felix

University of Sao Paulo, Sao Paulo, Brazil

Center for Longevity Economy Studies, Sao Paulo, Brazil

Andrzej Klimczuk

SGH Warsaw School of Economics, Warsaw, Poland

\section{Definitions}

Social entrepreneurship is usually understood as an economic activity that focuses on social values, goals, and investments that generates surpluses for social entrepreneurs as individuals, groups, and startups who are working for the benefit of communities, instead of strictly focusing mainly at the financial profit, economic values, and the benefit generated for shareholders or owners. Social entrepreneurship combines the production of goods, services, and knowledge in order to achieve both social and economic goals and allow for solidarity building. From a broader perspective, entities that are focused on social entrepreneurship are identified as parts of the social and solidarity economy. These are, for example, social enterprises, cooperatives, mutual organizations, self-help groups, charities, unions, fair trade companies, community enterprises, and time banks.

Social innovation is a key element of social entrepreneurship. Social innovation is usually understood as new strategies, concepts, products, services, and organizational forms that allow for the satisfaction of needs. Such innovations are created, in particular in the contact areas of various sectors of the social system. For example, these are spaces between the public sector, the private sector, and civil society. These innovations not only allow the solving of problems but also extend possibilities for public action.

\section{Overview}

\section{Concepts}

Social entrepreneurship and social innovation are basic terms derived from the discussion on the social and solidarity economy. Such an economic system may be defined as one that combines goals of three segments of society: the public sector understood as the employment policy and social inclusion; the private sector perceived as the corporate social responsibility (CSR) and activities focused at creating shared value (CSV); and the civil society identified in particular as entities of the third sector such as nongovernmental organizations (NGOs). The 
J. Felix, A. Klimczuk, Social Entrepreneurship and Social Innovation in Aging, [in:] D. Gu, M.E. Dupre (eds.), Encyclopedia of Gerontology and Population Aging, Springer, Cham 2020, pp. 1-8, https://doi.org/10.1007/978-3-319-69892-2 242-1.

social economy is usually described as the set of activities of social enterprises, which are also called as "hybrid organizations" or "dual-purpose entities." Such organizations are aimed at reconciling social and economic values so that business activities are subordinated to social objectives (Alter 2006). Examples of such entities include social cooperatives, work integration social enterprises (WISEs), NGOs engaged in business activities, the nonprofit companies, charities, social inclusion centers, as well as various social partnerships and networks that foster cooperation between entities from diverse sectors.

The more recent interpretation of the social economy is called the solidarity economy (Klimczuk 2015). This idea assumes that some manifestations of the "old" type of social enterprises, cooperative banks, and mutual insurance companies are already included in the mainstream economy, and thus they are no longer clearly related to solving social problems by citizens themselves with full awareness and responsibility of their actions. Thus, the solidarity economy focuses on "new" entities that want to foster solidarity as a response to inequality and injustice as well as adverse effects of the "informal economy" or the "gray market" (illegal activities, hidden from tax turnover of legal goods and services, e. g., provision of care for an older person outside the family without a job contract) and the "black market" (e.g., criminal activities, trafficking in illicit goods and services, and copyright infringement, i.e., extorting money from the older people by phone and other scams and frauds). The solidarity economy includes entities such as fair trade organizations (e.g., funding of local activity centers in the communities of origin of products by shortening of the distribution chain and the reduction in revenues of distributors), the movement of free and open-source software (FOSS; e.g., sharing of software source code allows other people to reuse this code and uses it to adapt the software to the needs of people with disabilities or to guarantee free access to the software), the open access movement (free and universal access to scientific and educational content primarily via the Internet), the Creative Commons movement (which focuses on the promotion of the use of copyleft licenses, the reuse of works by other authors, and increasing access to the public domain), and local currencies. Other examples of solidarity economy include commons-based peer production, which is the cooperation on joint projects via the Internet by people living in different places but taking into account resource sharing. For example, sharing of computing and power of information and communication technologies, creativity, time, and "selfdistribution" of tasks by people considering themselves to be the most competent to carry them out have a positive influence on the reduction of transaction costs and improvement of efficiency (Benkler 2006). Examples of such activities are included in the idea of e- 
J. Felix, A. Klimczuk, Social Entrepreneurship and Social Innovation in Aging, [in:] D. Gu, M.E. Dupre (eds.), Encyclopedia of Gerontology and Population Aging, Springer, Cham 2020, pp. 1-8, https://doi.org/10.1007/978-3-319-69892-2 242-1.

volunteering, Wikipedia, and online service for reporting problems in cities or e-consultations.

Social entrepreneurship is usually defined as an approach used by individuals, groups, and startup companies that allow them to develop, fund, and implement new and innovative solutions to social, cultural, or environmental issues. However, according to the European Commission's policy review (EC 2013), there is no agreement regarding the definition of social innovation. Partially this is because this term is still relatively new in the vocabulary of public policy analysis, and there are no specific policies to follow to foster social innovation. It is a quasi-concept similar to social capital and social investment. Despite the polysemy that characterizes them, they provide an analytical focus for identifying policy challenges and diagnosing their characteristics. Many authors choose to work with various notions and concepts of social innovation, which affect the identification and development of projects considered as examples of social entrepreneurship. The EC (2013) suggests using a mix of three interpretations of social innovation: (1) social innovation are new solutions that simultaneously meet a social need and lead to new or improved capabilities and relationships as well as better use of assets and resources. In other words, social innovation is good for society and enhances society's capacity to act; (2) social innovation must be structurally aimed at meeting a social need or significant public challenge; it must involve a new or significantly improved product, process, marketing method, and/or organizational model; and (3) social innovation is a process involving civil society actors or social economy entities that are developing new technologies, strategies, ideas, and/or organizations to meet social needs or solve social problems. Thus, social innovation is a fundamental element for social entrepreneurship, that is, innovative nonprofit businesses, and the fuel of the social and solidarity economy.

\section{Context}

Population aging is an unprecedented phenomenon in the history of capitalism. The intersection between the new demographic dynamics, the technological revolution, climate change, and a highly financialized economic model establishes a social reality in the twenty-first century. Since the global financial crisis in 2008, this socioeconomic framework has shown the limitations of traditional economic theory to meet the challenges posed by the aging population (Klimczuk 2015). Market remedies, instead of presenting solutions, only accentuated the severity of the consequences, especially social inequality, with the constraints of the social security systems. The social innovation emerged in this context to provide new forms to cope with the demands of an aging population.

Social enterprises that are innovative nonprofit businesses to meet the new needs of older 
J. Felix, A. Klimczuk, Social Entrepreneurship and Social Innovation in Aging, [in:] D. Gu, M.E. Dupre (eds.), Encyclopedia of Gerontology and Population Aging, Springer, Cham 2020, pp. 1-8, https://doi.org/10.1007/978-3-319-69892-2 242-1.

and aging persons and their families are a response to a long period of the commodification of social services. From the 1970s, the gradual deconstruction of the welfare state at various levels and paces in several countries has introduced the risk that the population aging is becoming another factor of the deepening of social inequality. The policy of fiscal austerity has returned the responsibility of old age almost entirely to older people themselves or to their families, just as before the rise of social security systems in the nineteenth century. Fiscal austerity policy has fostered a contrary interpretation of aging (Phillipson 2015). Older people started to be seen just as a high cost or a burden to the public sector, especially in the fields of the health sector and social security. Gradually, the states started to consider these sectors as costs and rush into delegating responsibilities to the private market or the traditional philanthropy. This is what Debert (1999) calls "reprivatization of old age." At some point, even the gerontological discourse started using notions such as "productive aging" and "positive aging" that could be considered as stimulus and incentives to older and aging persons to take responsibility and manage their own old age. Therefore, the growth of the social and solidarity economy can be considered as another manifestation of the public need to share the responsibility related to aging and care for older people with civil society and the private sector.

The process of sharing of responsibilities has become impossible in the economic environment of the twentieth century, where the state presented needs to force taxes, but taxpayers increasingly refuse to pay more taxes. Contemporarily the social and solidarity economy is disseminated as an alternative route or even as the main route in the case of population aging, due to potentially significant opportunities for innovation in goods, services, spaces, public schemes, and various specific industries. It is easy to notice that this is also a cost-effective way to establish solidarity with those at risk of social exclusion.

\section{Selected Research Topics in the Field}

\section{Changes in the Service Sector and the Development of Social Innovation in Aging}

Social innovation, as Kon (2018) highlights, breaks the economic paradigm that considers the service sector as "passive" and dependent on suppliers and that perceives innovation as feature a exclusive to the industrial sector. This scholar advocates an "integrated" view of production and consumption. With regard to aging, this finding is relevant, since the social entrepreneurship could be considered as a set of services to meet the needs of older people, their family members, and formal caregivers and the specialized care sector or aging services sector. Thus, the dependence on integration with the operator becomes more intense. A co-production 
J. Felix, A. Klimczuk, Social Entrepreneurship and Social Innovation in Aging, [in:] D. Gu, M.E. Dupre (eds.), Encyclopedia of Gerontology and Population Aging, Springer, Cham 2020, pp. 1-8, https://doi.org/10.1007/978-3-319-69892-2 242-1.

or co-creation should be established between producer and consumer. This particularity leads to the raise of the "innosumers" concept (Peine et al. 2014), which is consistent with studies that seek to understand the association between innovation, economic development, and social performance. This notion also focuses on interrelations both between service and industry as well as between innovation and targeted older consumers.

Theoretically, this Neo-Schumpeterian approach has been called "segmentalist" (Kon 2018) because it considers a heterogeneity of services - according to consumers - and the need to analyze innovation by specific subsectors. Aging services would be one of these subsectors. This approach can be a guide in a multidisciplinary vision that is no longer focused on a traditional definition of an innovation restricted to the product and process, as predicted by a Schumpeterian analysis (1961). Thus, the latest idea in the field of social innovation in aging is described as "ad hoc innovation," that is, new solutions related to the older person's need to be met by the service or an older-person-centered and integrated service. For example, implementing digital services in cities is related to expectations that these features will provide an impetus to extend distribution and access. However, several municipalities faced the implementation of such smart solutions with difficulties because they undervalued this integrated vision. Several empirical types of research could be cited here. However, filmmaker Ken Loach's "I, Daniel Blake" (2016) reflects what it is intended to expose about the adoption of disjointed innovation with the needs of the older user. The difficulty of actor Dave Johns' character in accessing the digitized systems demonstrates that incorporating a social attribute into services or products involves meeting not only the social demand but also the various perspectives affecting innovation.

\section{Social Entrepreneurship for Aging Populations: Boundaries and Challenges}

According to Schumpeter (1961), an entrepreneur must have two essential characteristics. The first one is the focus on innovation, and the second, of course, is to have the capital to fund his or her innovation. This may seem evident; however, often, the entrepreneur needs to hear the obvious, especially in the area of aging, where often a high level of emotion or sentimentality is involved in meeting the needs of older people.

There is no common definition of a social entrepreneur. However, the literature shows some consensus that a social entrepreneur often acts with little or no intention to gain personal profit or at least does not focus on economic values and commercial success. A social entrepreneur combines the passion of social mission with an image of business-like discipline, innovation, and determination commonly associated with, for instance, the high-tech pioneers of "Silicon 
J. Felix, A. Klimczuk, Social Entrepreneurship and Social Innovation in Aging, [in:] D. Gu, M.E. Dupre (eds.), Encyclopedia of Gerontology and Population Aging, Springer, Cham 2020, pp. 1-8, https://doi.org/10.1007/978-3-319-69892-2 242-1.

Valley" (Abu-Saifan 2012). In short, while the ultimate goal for an entrepreneur is the profit, in the case of a social entrepreneur, the main aim is to fulfill his or her social mission around those left behind by the traditional economy or to simply deliver potential solutions (social innovation) to community-based problems. Social entrepreneurs create, fund, and develop entities such as social cooperatives and nonprofit companies that are active as parts of the social and solidarity economy. It is worth noting that the most relevant for a social entrepreneur is to fill spaces and develop fields or sectors that were neglected or omitted by the public sector and commercial sector or areas that can be considered as state and/or market failures (e.g., care, unemployment, environmental protection, or fair trade).

So far, there is no closed list of features that characterizes a social entrepreneur in the aging sector or field. There is a need to establish guidelines for such activities. The social entrepreneur for aging populations must observe the social metamorphoses caused by the demographic transition and, mainly, the inability of the public sector and the private sector to respond to these new realities (e.g., to propose solutions for the disappearance and closing of public services in aging and depopulating regions; to establish new ways to produce and distribute goods and services in such regions). The Center for Longevity Economy Studies in Brazil defined three areas of orientation for actions in the field of aging, which can be considered as the mega drivers for transformations, needs, and opportunities: solidarity, environment, and technology (Felix 2019). It is a "SET Strategy for Aging." The economic policy of fiscal austerity in the twentyfirst century has proved incapable of providing answers to population aging in the face of changes in these three dimensions. Thus, these three words intersect with state and market failures. However, these sectors also require the innovation and creativity of social entrepreneurs for aging to present solutions. SET will also be the most sensitive segment for obtaining funding for NGOs, foundations, and other social entities.

For entrepreneurial action, SET words need to be understood in the broadest aspect and impact. For example, solidarity involves all aspects of long-term care, apparently, but also lifelong learning, digital exclusion, and technology, including the new "affection" to define social relations. Regarding the climate change or disasters with environmental consequences, older people have been the primary victims, whether in hurricanes on the European or North American coast or in the tragedy of the rupture of a dam in Mariana, in Brazil. However, climate change will also change consumer habits or demand education for new lifelong behavior. In terms of technology, it is clear that advances will mainly impact the world of work and inequalities. Such new technologies are, for example, described under the term "Fourth 
J. Felix, A. Klimczuk, Social Entrepreneurship and Social Innovation in Aging, [in:] D. Gu, M.E. Dupre (eds.), Encyclopedia of Gerontology and Population Aging, Springer, Cham 2020, pp. 1-8, https://doi.org/10.1007/978-3-319-69892-2 242-1.

Industrial Revolution," that is, economy characterized by the widespread use of automation, robotics, artificial intelligence, digitization, developments in genetics, nanotechnology, 3D printing, smart technologies, and biotechnology. "SET Strategy," however, would be comprehensive and needs a bottleneck for effective action for older people.

The framework recommended for the entrepreneur is to combine "SET Strategy" with the so-called 4Ms of aging - that stands for "matter (honors choice), mentality, mobility, and medication"-designed by the John A. Hartford Foundation in the United States (Fulmer et al. 2018). "What matters" could be actually changed with motivation and well-being that are crucial to act as a social entrepreneur. The $4 \mathrm{Ms}$ are already implemented in the test phase by the Institute for Healthcare Improvement in selected health systems in the United States to establish an age-friendly health system model. However, the guidelines of this model should also be considered in other sectors related to population aging.

\section{Social Entrepreneurship for Aging Populations in a Mixed Economy Context}

The socio-economic development, according to Klimczuk (2015), increasingly depends not only on factors related to one sector of the economy but on the relationships and stability in a number of sectors and across sectors. Social entrepreneurship in aging must be aware of possibilities of cooperation and an integrated vision among civil society, the public sector, and individuals to meet older people's needs. This new approach, which combines the actions and characteristics of various economic systems around aging, builds an ecosystem called the mixed economy of welfare, that is, a multisectoral approach to the challenges of the aging population. The most promising and successful actions around the world in the field of aging have taken advantage of this economic structure. In this perspective, the state, a traditional provider of well-being, reduces its role, but it does not disappear completely. It begins to use tools of governance that could be understood as the management of networks of entities, sharing responsibilities as well as co-production and co-creation with civil society and individuals who, in many cases, take the lead in designing and creating innovative solutions in forms of products, services, models, programs, spaces, environments, and organizational forms. Social entrepreneurship has high relevance in this ecosystem.

According to new approaches to the aging policy (public policy on aging), the contemporary actions in the field of aging are often taking place as parts of the attempts to establish the new economic systems such as the "longevity economy," the "silver economy," and the "care economy” (Zelizer 2008; Felix 2014, 2016). Klimczuk (2015), for example, recommends combining the silver economy (focused on the human capital of older people) with social and 
J. Felix, A. Klimczuk, Social Entrepreneurship and Social Innovation in Aging, [in:] D. Gu, M.E. Dupre (eds.), Encyclopedia of Gerontology and Population Aging, Springer, Cham 2020, pp. 1-8, https://doi.org/10.1007/978-3-319-69892-2 242-1.

solidarity economy (social capital) and the creative economy (cultural capital and creative capital). Thus, in the context of population aging, the entrepreneur must abandon the "silo view," focusing only on one of these systems, and should adopt an "overlapping view." This implies that lifelong learning entities, cultural centers, senior centers, community arts organizations, baby boomer organizations, third age groups, senior theaters, Universities of the Third Age (U3As), hospices, self-help groups, volunteers groups, senior citizens city councils, senior housing communities, intergenerational clubs, and NGOs can act together and in a coordinated way to offer support or social assistance in various environments for older people and to support the promotion of gerontology.

This integrated vision has already been adopted in France, for example, in its "silver economie" strategy (Bernard et al. 2013; Zimmer 2016). Notwithstanding the importance of an "information network economy in social entrepreneurship," as Benkler (2006) emphasizes, France has achieved some satisfactory results by encouraging NGOs such as the Silver Valley (2020) to stimulate startups focused on the needs of older people. The circulation of information in a network, through Internet portals such as SilverEco.fr (2020), and the construction of data sharing platforms and workshops or webinars were fundamental for the rise of social enterprises focused on aging as well as startups and business organizations. For example, the post office (Le Groupe La Poste) created a service which offers monitoring visit to older people living in isolated rural towns. Another example is a supermarket in the town of Tregastel in the Brittany region that has made tricycles available for volunteers to transport older people who live in nursing homes. They even have the chance to take a stroll along the seafront in addition to being able to maintain their purchasing activity.

\section{Future Directions of Research}

The rise of discourse on social innovation for aging populations at the beginning of the twentyfirst century already led to the development of some lists of potential research directions. For example, the European Innovation Partnership on Active and Healthy Ageing (EIP AHA), established by the EC, noticed that the crucial issue for the success of all efforts related to both technological and social innovations for older people is scaling up of the best solutions (EC 2015). The typology of five steps for innovation scaling up was developed and divided into two categories. The first category covers three first steps that refer to the solutions, models, products, and services that should be involved in scaling up: (1) building a database of proven best practices, (2) the assessment of the viability of best practices, and (3) the classification of 
J. Felix, A. Klimczuk, Social Entrepreneurship and Social Innovation in Aging, [in:] D. Gu, M.E. Dupre (eds.), Encyclopedia of Gerontology and Population Aging, Springer, Cham 2020, pp. 1-8, https://doi.org/10.1007/978-3-319-69892-2 242-1.

good practices for replication at the regional and local levels. The second category, with the final two steps, refers to approaches that may be used for further expansion: (4) facilitating partnerships for scaling up and (5) the implementation with the use of critical success factors and lessons learned. Thus, the research on social entrepreneurship and social innovation for aging populations should focus on each stage as well as on building the collaboration between various stakeholders to gather and select best practices and further support collective actions oriented at the "glocalization" of innovation developed in various countries, cultures, and environments.

Another list of research ideas could be created on the basis of recommendations provided in the report from the "Social Innovation in Ageing - the European Award" organized in 20132014 (Kesselring et al. 2014). There is a need to study 12 further scaling up activities or different diffusion strategies, which are (1) pilot projects that develop replicable model; (2) setting up local groups accordingly to the demand; (3) social franchising and consultancy; (4) national and international cooperation and promotion; (5) creating new facilities with public support at the local level; (6) transfer of model to similar organizations; (7) site visits, exchange, and training programs; (8) creating "academies" that attract and train volunteers and trainers (including online volunteering); (9) advocacy, mainstreaming aging, and promoting innovative initiatives through legal or regulatory tools; (10) establishing networks of independent organizations or umbrella organizations; (11) creating a self-sustaining user-to-user system; and (12) creating systems of accreditation or standardization of products and services. Moreover, there is a cross-cutting issue of funding and using various forms of financial, personnel, time, and other resources.

\section{Summary}

Social entrepreneurship has been an essential ally for aging policies. It is considered a creative and efficient response to the challenges faced by aging societies whose public budgets are strangled by the fiscal austerity policy imposed by neoliberalism (Tronto 2017). However, it is necessary for the social entrepreneur in aging to have a strategy based on the complexity of factors inherent in the demographic transition. An example of such a construct could be a framework based on a combination of the "SET Strategy for Aging" and the "4Ms of Aging." Social innovation must also be created by taking into account the complexity of the mixed economy of welfare or the economic ecosystem that is created at the intersections of the silver economy (longevity economy), the social and solidarity economy, and the creative economy. 
J. Felix, A. Klimczuk, Social Entrepreneurship and Social Innovation in Aging, [in:] D. Gu, M.E. Dupre (eds.), Encyclopedia of Gerontology and Population Aging, Springer, Cham 2020, pp. 1-8, https://doi.org/10.1007/978-3-319-69892-2 242-1.

A few warning messages should also be given to potential social entrepreneurs in the field of aging. Firstly, it is crucial to be aware that, in the political environment, social innovation can provoke political reactions, since it shows a failure of the state or the market. This may require considerable negotiation skills, especially with public entities and institutional relations. Secondly, the social entrepreneur must be concerned with offering diverse solutions rather than just a traditional decommodified solution. Thirdly, because social innovation must be customized or "ad hoc," it will hardly be replicated in time and space, so by definition, it is limited. Scaling up of a proven solution nationally, regionally, or globally thus requires adaptations, specific strategies, and further research. The last warning is to view social innovation as any other innovation from the perspective of the research and development (R\&D) investment. Innovation - and social innovation is not an exception - is always dynamic and constitutes a permanent work in progress. It is common to imagine that social innovation arises without the need for research or is the result of the goodness of heart. It is also typical to wrongly imagine that once the enterprise has been implemented, the research can be stopped. Disregarding any of these warnings can significantly jeopardize social entrepreneurship in aging populations.

\section{References}

Abu-Saifan S (2012) Social entrepreneurship: definition and boundaries. Technol Innov

$$
\text { Manag Rev 2:22-27. https://doi.org/10.22215/timreview/523 }
$$

Alter K (2006) Social Enterprise typology. Virtue Ventures LLC, Washington, DC

Benkler Y (2006) The wealth of networks: how social production transforms markets and freedom. Yale University Press, New Haven, London

Bernard C, Hallal S, Nicolai J-P (2013) La Silver Economie, une opportunite de croissance pour la France [The silver economy: a growth opportunity for France]. Commissariat General a la Strategie et a la prospective, Paris

Debert GG (1999) A reinvenęao da velhice [The reinvention of old age]. Edusp, Sao Paulo

EC (European Commission) (2013) Social innovation research in the European Union: approaches, findings and future directions (Policy review). Publications Office of the European Union, Luxembourg

EC (European Commission) (2015) European scaling-up strategy in active and healthy ageing. European Commission, Brussels

Felix J (2014) "Economia do Care" e "Economia da Longevidade": o envelhecimento 
J. Felix, A. Klimczuk, Social Entrepreneurship and Social Innovation in Aging, [in:] D. Gu, M.E. Dupre (eds.), Encyclopedia of Gerontology and Population Aging, Springer, Cham 2020, pp. 1-8, https://doi.org/10.1007/978-3-319-69892-2 242-1.

populacional a partir de novos conceitos: [Care economy and longevity economy: the population ageing's research from new concepts]. Argumentation 6:44-63.

https://doi.org/10.18315/argumentum.v6i1.6432

Felix J (2016) Silver economy: opportunities and challenges to Brazil adopt the European Union's strategy. Innov Eur J Soc Sci Res 29:115-133.

https://doi.org/10.1080/13511610.2016.1166937

Felix J (2019) Economia da longevidade: O envelhecimento populacional muito alem da previdencia [Economics of longevity: population aging far beyond social security]. Editora 106, Sao Paulo

Fulmer T, Mate KS, Berman A (2018) The age-friendly health system imperative. J Am Geriatr Soc 66:22-24. https://doi.org/10.1111/jgs.15076

Kesselring A, Smith S, Dobner S, Schrammel M (2014) Social innovation for active and healthy ageing: a case study collection. King Baudouin Foundation, Brussels

Klimczuk A (2015) Economic foundations for creative ageing policy, volume I: context and considerations. Palgrave Macmillan, New York, Basingstoke, Hampshire. https://doi.org/10.1057/9781137465337

Kon A (2018) A inovaęao nos servięos como instrumento para a Inovaęao Social: uma visao integrativa [Services innovation as a tool to social innovation: an integrative vision]. Brazil J Polit Econ 38:584-605. https://doi.org/10.1590/0101-35172018-2814

Peine A, Rollwagen I, Neven L (2014) The rise of the "innosumer"—rethinking older technology users. Technol Forecast Soc Chang 82:199-214. https://doi. org/10.1016/j.techfore.2013.06.013

Phillipson C (2015) The political economy of longevity: developing new forms of solidarity for later life. Sociol $Q$ 56:80-100. https://doi.org/10.1111/tsq.12082

Schumpeter JA (1961) The theory of economic development: an inquiry into profits, capital, credit, interest, and the business cycle. OUP, New York

Silver Valley (2020) Silver Valley. https://silvervalley.fr/. Accessed 11 Jul 2020

SilverEco (2020) SilverEco. https://www.silvereco.fr/. Accessed 11 Jul 2020

Tronto J (2017) There is an alternative: homines curans and the limits of neoliberalism. Int J Care Caring 1:27-43. https://doi.org/10.1332/239788217X14866281687583

Zelizer V (2008) L'Economie du care [The care economy]. Revue Franęaise de SocioEconomie 2:13. https://doi.org/10.3917/rfse.002.0013

Zimmer B (2016) Enjeux et opportunites de la filiere Silver economie: exemple de la France 
J. Felix, A. Klimczuk, Social Entrepreneurship and Social Innovation in Aging, [in:] D. Gu, M.E. Dupre (eds.), Encyclopedia of Gerontology and Population Aging, Springer, Cham 2020, pp. 1-8, https://doi.org/10.1007/978-3-319-69892-2 242-1.

[Challenges and opportunity of the silver economy sector: example from France].

Angewandte Gerontologie Appliquee 1:41-42. https://doi.org/10.1024/2297-5160/a000030 